\title{
A SUPERAÇÃO DA DICOTOMIA OBJETIVIDADE X SUBJETIVIDADE NA GEOGRAFIA E SEUS REFLEXOS SOBRE OS ESTUDOS DAS RELAÇÕES DE ESPACIAIS DE PODER $E$ OS CONCEITOS DE TERRITÓRIO $E$ TERRITORIALIDADE
}

Jaime Bernardo Neto ${ }^{1}$

Resumo: Em consonância com o que ocorria em outras áreas do conhecimento na segunda metade do século $\mathrm{XX}$, a dicotomia materialidade $x$ simbolismo (ou objetividade $x$ subjetividade) começa a ser superada na Geografia - ao menos no que tange à análise das relações espaciais de poder - ao longo da década de 1970, graças ao aporte das ideias de pensadores como Michael Foucault e Pierre Bourdieu. Esse avanço teórico trouxe consigo significativas transformações sobre a principal ferramenta conceitual da Geografia para análise dessas relações: 0 conceito de território e seu derivado, a territorialidade. Este artigo tem por objetivo discorrer sobre esta transformação teórico-metodológica, particularmente no que tange às mudanças sobre o par conceitual território-territorialidade dela decorrente.

Palavras-chave: Geografia. Materialidade. Simbolismo. Território. Territorialidade.

\section{THE OVERCOMING OF OBJECTIVITY $X$ SUBJECTIVITY DICHOTOMY IN GEOGRAPHY AND IT'S REPERCUSSION OVER STUDIES ABOUT SPATIAL POWER RELATIONS AND THE CONCEPTS OF TERRITORY AND TERRITORIALITY}

Abstract: In consonance to what was happening at other areas of knowledge at Twentieth Century's second half, the dichotomy materiality $x$ symbolism (or objectivity $x$ subjectivity) began to be overcame in Geography - at least in what regards spatial power relations - from the seventies on, due to contribution from the ideas of thinkers such as Michael Foucault and Pierre Bourdieu. This theoretical advancement brought with it significant chances over Geography's main conceptual tool to analyze these relations: the concept of territory and it's derivative, territoriality. The following article aims to discuss over this theoretical-methodological transformation, particularly with regard to changes in the conceptual pair territoryterritoriality resulting from it.

Keywords: Geography. Materiality. Symbolism. Territory. Territoriality.

\section{LA SUPERACIÓN DE LA DICOTOMÍA OBJETIVIDAD x SUBJETIVIDAD EN LA GEOGRAFÍA $Y$ SU REPERCUSIÓN SOBRE LOS ESTUDIOS DE LAS RELACIONES ESPACIALES DE PODER Y LOS CONCEPTOS DE TERRITORIO Y TERRITORIALIDAD}

RESUMÉN: En línea con lo que ocurrió en otras áreas del conocimiento en la segunda mitad del siglo XX, la dicotomía materialidad $\mathrm{x}$ simbolismo (u objetividad $\mathrm{X}$ subjetividad) comienza a superarse en Geografía - al menos con respecto al análisis de las relaciones de poder espacial - a partir de la década de 1970, gracias al aporte de las ideas de pensadores como Michael Foucault y Pierre Bourdieu. Este avance teórico trajo consigo cambios significativos en la principal herramienta conceptual de Geografía para analizar estas relaciones: el concepto de territorio y su derivada, la territorialidad. Este artículo tiene como objetivo discutir esta transformación teóricometodológica, particularmente con respecto a los cambios en el par conceptual territorio-territorialidad resultante de ella.

\footnotetext{
${ }^{1}$ Instituto Federal do Espírito Santo, Coordenadoria da Licenciatura em Geografia, Nova Venécia, Brasil, jbn83@hotmail.com.br, https://orcid.org/0000-0002-9730-2747
} 
Palabras clave: Geografía. Materialidad. Simbolismo. Territorio. Territorialidad.

\section{Introdução}

A década de 1970 marca um momento de rupturas e transformações sobre a forma como a Geografia abordava as relações espaciais de poder. Obras como Por uma Geografia do Poder, de Claude Raffestin (1993[1980]) e Espaço e Poder, de Paul Claval (1979[1978]), originalmente publicadas em fins da referida década, possuem um verdadeiro teor de manifesto contra as perspectivas teóricometodológicas reinantes até então nessa ciência, cujas análises geralmente tinham um enfoque unidimensional (demasiado focado na dimensão material/tangível da realidade) e estadocêntrico (demasiado focado no Estado).

Essa ruptura, por sua vez, demandava a reconstrução do arcabouço teórico utilizado pela Geografia para pensar e interpretar as relações espaciais de poder, reconhecendo que elas ocorrem entre atores diversos e nas mais diversas escalas (não sendo, portanto, algo específico ou restrito ao Estado ou às relações propriamente econômico-capitalistas) e partindo da premissa de que a realidade é uma complexa amálgama de elementos simbólicos e materiais que se influenciam mutuamente, o que implica a necessidade de entender os elos entre as relações de poder e o complexo jogo existente entre as representações da realidade e as identidades por elas produzidas/influenciadas.

Sendo o conceito de território a principal ferramenta teórico-conceitual da Geografia para a análise das relações espaciais de poder, essas transformações teórico-metodológicas tiveram forte impacto sobre a forma como este conceito e seus derivados (como a territorialidade) eram utilizados pela disciplina, sendo o berço, portanto, de sua semântica conceitual hegemônica dentro da disciplina atualmente.

O presente artigo tem por objetivo discorrer sobre este processo, abordando algumas de suas consequências, sobretudo no que tange às transformações pelas quais o uso dos conceitos de território e territorialidade pela Geografia tem passado desde então, mas também buscando contribuir com a reconstituição de sua gênese, a qual deriva de um movimento mais amplo na Teoria Social (e que transcende, portanto, a Geografia) decorrente do impacto das ideias de pensadores como Cornelius Castoriadis, Pierre Bourdieu e Michel Foucault, dentre outros, que embora claramente situados à esquerda do espectro político, romperam com muitos 
pressupostos teóricos tanto do marxismo ortodoxo ${ }^{2}$ quanto daquilo que se poderia chamar de estruturalismo-marxista ${ }^{3}$.

Comecemos, então, por tratar da emergência dessa nova vertente da Teoria Social Crítica para posteriormente tratarmos de seus impactos sobre a Geografia e sobre a forma como o conceito de território vem sendo usado nessa disciplina desde então.

\section{As relações de poder e a amálgama entre as dimensões simbólica e material da realidade}

As formas de domínio mais eficazes e mais difíceis de serem combatidas são justamente aquelas que normalmente não são percebidas como tais, e esse mesmo princípio é válido para os aspectos espaciais das relações de poder. Todavia, por um legado positivista e empirista das Ciências Sociais em geral - a qual está presente mesmo em teorias que se dizem críticas, como ressalta Bourdieu (2012, p. 120) - essa premissa nem sempre embasou as Ciências Sociais (e dentre elas a Geografia, em particular).

Em linhas gerais, sua ascensão na Teoria Social como um todo parece remeter à segunda metade do século XX e está muito ligada às ideias de pensadores como Castoriadis (1982), Foucault (2004) e Bourdieu (2012), dentre outros. Nas palavras desse último:

[...] Como em outros tempos não se queria reconhecê-lo nas situações em que ele [o poder] entrava pelos olhos dentro, não é inútil lembrar que [...] é necessário saber descobri-lo onde ele se deixa ver menos, onde ele é mais completamente ignorado, portanto, reconhecido: o poder simbólico é, com efeito, esse poder invisível o qual só pode ser exercido com a cumplicidade daqueles que não querem saber que lhe estão sujeitos ou mesmo que o exercem. (BOURDIEU, 2012, p. 7-8).

Gradativamente a Teoria Social Crítica parece ter reconhecido que primar pelo poder inerente a construções simbólicas/imateriais não significa negar a importância da materialidade e que, pelo contrário, tal opção se mostrava um possível caminho para se superar os impasses e limitações de formas dicotômicas

\footnotetext{
2 Utiliza-se aqui esse termo, tal como o faz Wallerstein (2006), para designar a interpretação hegemônica das obras de Marx que foi disseminada entre fins do século XIX e início do século XX pelo Partido Social Democrata Alemão e, posteriormente, pelos Bolcheviques.

${ }_{3}^{3}$ Usamos este termo para designar uma vertente estruturalista que se fundamentava em uma espécie de "determinismo econômico", o qual compartilha de muitas premissas do marxismo ortodoxo, como bem descrito por Castoriadis (1982).
} 
de se apreender o real vividas por praticamente todas as áreas das Humanidades na segunda metade do século $X X$.

A maioria das Ciências Sociais e Humanas, neste contexto, estava a vivenciar a superação de abordagens que poderíamos chamar de objetivistas e/ou funcionalistas da realidade social (inicialmente positivistas e, posteriormente, neopositivistas), que gradativamente perdiam espaço para um par dicotômico de novas tendências: de um lado, aquelas fundadas num estruturalismo praticamente fundido ao marxismo ortodoxo, de viés economicista, e de outro as abordagens que poderíamos designar de subjetivistas, de matriz fenomenológica. As primeiras primavam tanto pelos aspectos estruturais a ponto de quase negar o papel dos sujeitos e as últimas supervalorizavam os indivíduos e sua subjetividade em detrimento do meio em que se inserem, sendo ambas igualmente incapazes de captar a amálgama entre essas dimensões do real e sua influência mútua/recíproca.

A superação deste empasse parece, portanto, remeter à uma vertente da Teria Social Crítica que se consolida ao longo dos anos de 1960 e 1970 que parte da premissa de que a realidade é constituída pela união indissociável dessas duas dimensões (simbólica e material) e que elas se equivalem em importância e se influenciam mutuamente. Dentre os ícones desta nova tendência, podemos citar pensadores como Michel Foucault, Pierre Bourdieu e Cornelius Castoriadis.

Esta premissa foi o caminho que pesquisadores como Chartier (1990) e Godelier (1981), por exemplo, buscaram para tentar superar as barreiras oriundas da referida dicotomia em suas áreas de conhecimento (História e Antropologia, respectivamente). Nas palavras de Godelier (1981):

Em resumo, há ideal por toda parte, o que não implica que tudo seja
ideal no real (social). As ideias não aparecem como "uma instância"
separada das relações sociais, re-apresentando-as como
demasiadamente tarde na consciência e ao pensamento. O ideal
está, portanto, no pensamento em todas as suas funções, presente e
atuante em todas as atividades do homem, que só existe em
sociedade, só existe como sociedade. O ideal não se opõe ao
material, já que pensar é pôr em movimento a matéria, o cérebro. A
ideia é uma realidade não-sensível, uma realidade que não é
imediatamente evidente. O ideal é, portanto, o que faz o pensamento,
e sua diversidade, sua complexidade correspondem à distinção e à
complexidade das funções do pensamento. [...] (GODELIER, 1981,
p.187).

Nas diversas Ciências Humanas e Sociais, portanto, parece gradativamente ter se consolidado o reconhecimento de que "é esta dupla verdade, objectiva (sic) e subjectiva (sic), que constitui a verdade completa do mundo social" (BOURDIEU, 2012, p.53), e de que era necessário, portanto, "acabar com os falsos debates 
desenvolvidos em torno da partilha, tida como irredutível, entre a objetividade das estruturas [...] e a subjetividade das representações" (CHARTIER, 1990, p. 17-18) e reconhecer que as "realidades ideais aparecem não como efeitos no pensamento das relações sociais, mas como um dos seus componentes internos necessários, condição tanto da sua formação, como da sua reprodução [...]" (GODELIER, 1981, p.186).

$\mathrm{Na}$ análise das relações de poder, portanto, o corolário destas premissas é o pressuposto de que o entendimento dessas relações não deve ser buscado apenas na materialidade, nos meios propriamente tangíveis, mas igualmente no universo simbólico. Essas construções imateriais são parte do universo social tanto quanto sua materialidade, e indubitavelmente pesam na balança do poder. Como ressalta Chartier (1990), buscar sua gênese é, portanto, tão importante quando analisar o contexto em que se inserem e que contribuem para modelar:

\begin{abstract}
As representações do mundo social [...], embora aspirem a universalidade de um diagnóstico fundado na razão, são sempre determinadas pelo interesse de grupos que as forjam. Daí, para cada caso, o necessário relacionamento dos discursos proferidos com a posição de quem os utiliza. As percepções do social não são de forma alguma discursos neutros: produzem estratégias e práticas (sociais, escolares, políticas) que tendem a impor uma autoridade a custa de outros, por elas menosprezados, a legitimar um projeto reformador ou a justificar, aos próprios indivíduos, as suas escolhas e condutas. Por isso, [...] [a] investigação sobre as representações supõem-nas como estando sempre colocadas num campo de concorrências e competições cujos desafios se enunciam em termos de poder e de dominação. As lutas de representações têm tanta importância quanto as lutas econômicas para se compreender os mecanismos pelos quais um grupo impõe, ou tenta impor, a sua concepção do mundo social, os valores que são os seus, e o seu domínio. Ocupar-se dos conflitos de classificações ou de delimitações não é, portanto, afastar-se do social [...], muito pelo contrário, consiste em localizar os pontos de afrontamento mais decisivos quanto menos imediatamente materiais. (CHARTIER, 1990, p. 17, grifo nosso).
\end{abstract}

Como afirma Castoriadis (1982, p. 142), "Tudo o que se nos apresenta, no mundo social-histórico, está indissociavelmente entrelaçado com o simbólico". Os seres humanos e as sociedades e grupos sociais que estes constituem agem, portanto, não em função da materialidade stricto sensu, mas de suas representações da realidade. Nas palavras de Chartier (1990, p. 177), não pode "haver prática ou estrutura que não seja produzida pelas representações, contraditórias e em confronto, pelas quais os indivíduos e os grupos dão sentido ao mundo que é o deles". Deve-se, portanto, "considerar, corolariamente, estas representações coletivas como matrizes do próprio mundo social" (CHARTIER, 1990, p. 183). 
O segredo desse "poder" imanente ao simbolismo advém, segundo esses autores, da naturalização que ele tende a estabelecer de uma certa forma de pensar, de repartir e ordenar abstratamente a realidade social, e que, consequentemente, resulta em uma naturalização dos comportamentos que se baseiam nessa construção cultural, imaterial. Esse mecanismo tende a ser tão mais forte quanto menos seu caráter arbitrário for evidente, e aqui se deve ressaltar, tal qual o faz incessantemente Bourdieu (2012), que toda e qualquer forma de recortar e representar a realidade é arbitrária, e que, como ressalta Castoriadis (1982), essas representações têm fundamento tanto em elementos materiais/tangíveis/visíveis quanto no imaginário social ${ }^{4}$, essa espécie de inconsciente coletivo - o que em grande medida explica nossa tendência em naturalizá-las.

Por essa razão, segundo Bourdieu (2012, p.15), o poder simbólico só pode ser destruído por meio da tomada de consciência de seu caráter arbitrário, daí a importância em "reconstruir em cada caso o trabalho histórico de que são produto as divisões sociais e a visão social dessas divisões" (BOURDIEU, 2012, p. 157). A imposição de um sistema de representações é, portanto, uma maneira de assegurar um domínio com menor necessidade de imposição coerciva por meio da força física. Quanto maior for a eficácia dessa imposição simbólica por parte dos opressores, menor é a necessidade da violência material para submeter os oprimidos, como ressalta Godelier (1981):

[...] violência e consentimento não são, no fundo de cada um dos dois, realidades mutuamente exclusivas. Para durar, todo poder de dominação e, mais que todos, os que surgem da força brutal da guerra e da conquista deve comportar e compor as duas condições de seu exercício. Sem dúvida, as proporções variarão segundo as circunstâncias e as resistências, mas até mesmo o poder de dominação menos contestado, mais profundamente aceito, contém sempre a ameaça virtual de recorrer à violência assim que o consentimento enfraqueça ou dê lugar à recusa, ou mesmo à resistência. Não há dominação sem violência, mesmo que essa se limite a ficar ao longe. Portanto, é vão imaginar um poder de dominação durável que não repouse sobre a pura violência ou sobre um consentimento total. Estes seriam casos-limite que, na melhor das situações, se refeririam a estados transitórios, senão efêmeros, da evolução histórica. (GODELIER, 1981, p. 192).

Em maior ou menor grau, nenhuma relação de poder, ao menos em âmbito coletivo, se perpetua com base apenas no consentimento ou apenas na violência pura. Mesmo o mais violento dos regimes de dominação possui algum elemento

\footnotetext{
${ }^{4}$ Segundo Castoriadis (1982, p.169), a construção do universo simbólico remete ao menos a três campos distintos: o real (ou, antes, aquilo que é percebido como real), o racional e o imaginário, sendo este último aquilo que molda uma espécie de inconsciente coletivo, sem o qual seria impossível essa construção simbólica.
} 
discursivo que busque legitimá-lo, tal qual mesmo o mais eficaz dos domínios baseados no consentimento sempre considera a possibilidade de recorrer à violência, caso isso se mostre necessário. Todavia, como ressalta Godelier (1981, p.192), "dos dois componentes do poder, a força mais forte não é a violência dos dominadores, mas o consentimento dos dominados em sua dominação", já que em função da menor necessidade de vigilância direta, por assim dizer, as relações de poder com base no consentimento têm potencial para ter maior eficácia e abrangência (tanto temporal, quanto territorial e demográfica) do que aquelas baseadas fundamentalmente na coerção física.

A obtenção desse consentimento aparentemente espontâneo, entretanto, não costuma ser algo tão espontâneo - tende a ser antes "o resultado de uma educação, de uma cultura, de uma 'formação' do indivíduo, de uma produção de homens e mulheres capazes de reproduzir sua sociedade" (GODELIER, 1981, p. 192).

É fato que a tradição marxista ortodoxa não negligenciou por completo essa complexidade das relações de poder em âmbito coletivo. Marx conseguiu perceber, ainda de maneira um pouco restrita, a importância da dimensão imaterial da vida social, a qual ele procurou captar, por exemplo, por meio de conceitos como "ideologia" (que, na sua acepção original, seria a forma como as classes dominantes na sociedade tendem a impor seus objetivos e sua visão de mundo aos dominados, fazendo-os crer e agir em prol desses interesses que não são propriamente os de sua classe e que perpetuam, por corolário, sua condição de explorado, oprimido) e "superestrutura" (que seria o conjunto dessas construções imateriais com o intuito de legitimar o modo de produção vigente e seus aspectos materiais, tangíveis - a "infraestrutura").

Todavia, não obstante já demonstrasse preocupação e atenção acerca da influência da imaterialidade sobre a realidade visível e tangível, a perspectiva de Marx e de uma certa tradição marxista (sobretudo em sua vertente ortodoxa ${ }^{5}$ ) sobre o universo simbólico e sua relação com a materialidade à qual se encontra entrelaçada parece bastante limitada quando comparada ao patamar que esta discussão atinge a partir das décadas de 1960 e 1970. Primeiramente, porque a tradição marxista não reconhecia suas próprias representações da realidade enquanto tais, tomando-as como a própria realidade tangível e concreta (BOUDIEU,

\footnotetext{
${ }^{5}$ Outras leituras das obras de Marx, como a de Gramsci, por exemplo, parecem lidar melhor com essas imbricações entre o material e o simbólico do que sua vertente ortodoxa. Todavia, o crescimento da influência dessas outras vertentes marxistas (heterodoxas) sobre as Ciências Sociais também parecem ser um fenômeno da segunda metade do século XX.
} 
1989 , p. 133$)^{6}$, como a verdade sobre o universo social, como afirmava Foucault (2004), e também por se fundamentar, como afirma Castoriadis (1986, p.140), em uma visão funcionalista do universo simbólico, que tende a ser interpretado como um construto com o único propósito de legitimar e viabilizar a "infraestrutura". Ele pode e sem dúvida serve a isso, mas não apenas a isso, já que é antes elemento gnosiológico por assim dizer, sendo fundamental às relações sociais como um todo.

Se quisermos, portanto, romper de fato com a dicotomia materialidade $\mathrm{x}$ simbolismo e captarmos as inter-relações entre essas dimensões inerentemente imbricadas e mutuamente influenciadas, faz-se necessário redefinirmos esses conceitos, tomando a ideologia, por exemplo, não como uma interpretação inverídica da realidade social, já que, como apontava Foucault (2004), provém daí a grande limitação desse instrumental teórico-metodológico proveniente do marxismo ortodoxo em apreender a dimensão imaterial das relações de poder. Nesse sentido, seria mais funcional entender a ideologia como um conjunto de representações compartilhadas consciente ou inconscientemente por um grupo que legitimam um determinado modelo de sociedade.

Esse princípio e seus corolários parecem ser algo bastante reconhecido e aceito no pensamento geográfico contemporâneo, o qual seguiu uma trajetória semelhante ao que ocorria em disciplinas próximas (inclusive no que tange ao momento em que isso começa a ocorrer, que é principalmente a partir da década de 1970), buscando caminhos parecidos para se superar a dualidade objetividade $x$ subjetividade, materialidade $x$ simbolismo, reconhecendo-as como dimensões indissociáveis e mutuamente influenciadas da realidade, como se constata em obras contemporâneas sobre questões teóricas e epistemológicas da disciplina, como as de Claval (2012) e Haesbaert (2010 e 2012), por exemplo. Nas palavras deste último:

O "real" [...] é também, sempre, uma construção, mas não apenas uma construção discursiva, mental, mergulhado que está dentro desse jogo indissociável entre os campos ideal e material, subjetivo e objetivo. Em sua complexidade, esse real se apresenta como um conjunto ao mesmo tempo contraditório e ambivalente de processos sociais, de práticas materiais e imateriais, numa espécie de agenciamento, como diria Deleuze, entre corpos e enunciados, vida material e discursiva, sem que um tenha, a priori e obrigatoriamente, preponderância sobre o outro. (HAESBAERT, 2010, p. 177).

As obras Jean Gottmann (1973), Claude Raffestin (1993[1980]) e Paul Claval (1979[1978]) foram algumas das primeiras a trazer tais premissas teóricas à Geografia para se pensar as relações espaciais de poder, ainda nos anos de 1970.

\footnotetext{
${ }^{6}$ Ver também o capítulo VI, que o autor dedica quase exclusivamente a esse tema.
} 
Este último autor, em Espaço e Poder, obra que tem certo "teor de manifesto" no sentido de uma ruptura com a Geografia Política Clássica, assim escreve:

\begin{abstract}
O espaço é um dos apoios privilegiados da atividade simbólica. Ele é percebido e valorizado de forma diversa pelos que o habilitam ou the dão valor: à extensão que ocupam, percorrem e utilizam se superpõe, em seu espírito, aquela que conhecem, amam e que é para eles signo de segurança, motivo de orgulho ou fonte de apego. $O$ espaço vive assim sob a forma de imagens mentais ${ }^{7}$; elas são tão importantes para compreender a configuração dos grupos e forças que trabalham quanto às qualidades reais do território que ocupam. (CLAVAL, 1979, p. 20-21)
\end{abstract}

Segundo Claval (2012), esse movimento de incorporação da dimensão simbólica na análise das relações espaciais de poder tem suas raízes primeiras na "redescoberta" da subjetividade inerente às relações espaciais que ocorre com a "erupção" da influência fenomenológica sobre a Geografia. Esse foi, de certa forma, um primeiro movimento de questionamento e ruptura com o objetivismo que historicamente caracterizou a disciplina, presente tanto nas escolas clássicas e neopositivistas como entre os estruturalistas e marxistas (ainda que com certa ressalva no caso desses últimos, como já discorrido).

Essa ponte para se superar a dicotomia objetividade $\mathrm{x}$ subjetividade, entretanto, parece só ter sido devidamente explorada na análise das relações espaciais de poder em um momento posterior à emergência da fenomenologia e ao início da renovação crítica da disciplina, quando alguns pensadores que outrora defendiam que as abordagens humanistas seriam "desligadas dos problemas da atualidade" (crítica que era comumente feita por geógrafos de vertentes marxistas) perceberam que, pelo contrário, "a tônica colocada na experiência individual não desvia das questões sociais" e aceitaram que, de fato, essa opção teórica "permite abordá-las [as relações espaciais de poder] de maneira mais rigorosa, a partir de hipóteses mais realistas" (CLAVAL, 2012, p. 239).

A partir de então, cada vez mais se tem a certeza de que, como afirma Claval (2012, p.374), a "[...] compreensão do mundo contemporâneo implica a exploração das representações geográficas que partilham as massas populares":

\footnotetext{
Fazer estudos de geopolítica é unir-se a essas representações e destacar o papel que têm nos conflitos e nas escolhas efetuadas pelos diferentes atores.

A elaboração das representações e a sua divulgação constituem assim um aspecto do jogo social há muito tempo negligenciado. [...] Nas situações que formam a trama da existência coletiva, a mobilização da força física ou o recurso ao dinheiro não desempenham um papel mais fundamental que o
}

\footnotetext{
7 Deve-se destacar aqui que esse conceito ("imagens mentais") é muito semelhante ao de representações, que posteriormente passou a ser utilizado por esse autor - ver Claval (2012) - em substituição a ele.
} 
prestígio, o estatuto merecido ou a autoridade legítima. $O$ universo dos homens é feito tanto de discursos como de realidades tangíveis. A ideia pesa tanto quanto o material. As duas vertentes são complementares e indissociáveis.

[...] O jogo social não se restringe às distinções de classe; baseia-se da mesma forma na maneira como a palavra e a escrita modelam as sensibilidades e fazem compartilhar as mesmas representações. (CLAVAL, 2012, p. 247).

No atual momento, não seria exagero dizer que soam bastante retrógradas no meio acadêmico da Geografia posições teóricas e filosóficas que neguem que "[...] os discursos dos geógrafos "[...] 'criam' categorias geográficas e desenham os contornos 'de espaços' sobre os quais ninguém tinha até então consciência" (CLAVAL, 2012, p. 249), e que o estudo acerca da história dessas representações de tempo-espaço têm a virtude de nos revelar que "[...] entidades geográficas que nos parecem naturalmente se impor são frequentemente construções relativamente recentes" (CLAVAL, 2012, p. 250).

\section{Para além do Estado e da Materialidade: a evolução dos conceitos de território e territorialidade na Geografia}

Como já mencionado, tais reflexões sobre a indissociabilidade entre as dimensões material e simbólica da vida social, em consonância com esse movimento mais amplo da Teoria Social Crítica rumo a essa ruptura, descrito no item anterior, começam a ser trazidas à Geografia por meio de trabalhos publicados a partir da década de 1970. E tal fenômeno gerou significativas transformações sobre o principal conceito que a Geografia utiliza como ferramenta teórica para os estudos das relações espaciais de poder - o conceito de território.

Este conceito, entretanto, talvez seja, dentre aqueles mais caros à Geografia, o que apresentou e ainda apresenta maior polissemia, dentro ou fora da disciplina, como discorre Haesbaert (2012):

Apesar de ser um conceito central para a Geografia, o território e a territorialidade, por dizerem respeito à espacialidade humana, têm uma certa tradição também em outras áreas, cada uma com enfoque centrado em determinada perspectiva. Enquanto o geógrafo tende a enfatizar a materialidade do território, em suas múltiplas dimensões [...], a Ciência Política enfatiza a sua construção a partir de relações de poder (na maioria das vezes, ligada à concepção de Estado); a Economia, que prefere a noção de espaço à de território, percebe-o muitas vezes como um fator locacional ou como uma das bases da produção (enquanto "força produtiva"); a Antropologia destaca sua dimensão simbólica, principalmente no estudo das sociedades ditas tradicionais (mas também no tratamento do neotribalismo contemporâneo); a Sociologia o enfoca a partir de suas intervenções nas relações sociais, em sentido amplo, e a Psicologia, finalmente, incorpora-o no debate sobre a construção da subjetividade ou 
da identidade pessoal, ampliando-o até a escala do indivíduo (HAESBAERT, 2012, p. 37).

$\mathrm{Na}$ Geografia, especificamente, como mencionado pelo autor, seu uso inicialmente caracterizou-se pela primazia dada à materialidade das relações sociais, tanto na dimensão política quanto econômica. Isso não quer dizer, entretanto, que o universo simbólico estivesse totalmente ausente da forma como o conceito de território era concebido.

Apesar deste conceito (território) historicamente ter primado pela materialidade das relações espaciais de poder, desde os primórdios de sua utilização pela Geografia Moderna ele tangenciava a dimensão simbólica dessas relações, como se constata desde Ratzel (conforme afirma Haesbaert [2012]), embora fosse pouco capaz de articulá-la à dimensão material de forma eficaz, como se espera das ferramentas conceituais nas Ciências Sociais - e nem poderia ser diferente, já que a própria Geografia, anteriormente a meados do Século XX, não era ainda considerada uma Ciência Social pela maioria dos seus autores, como se constata em Andrade (1987) e Moraes (2007).

Nesse sentido, as obras de Raffestin (1993[1980]) e Claval (1979[1978]) soaram, a seu tempo, como verdadeiros manifestos de ruptura com uma tradição demasiado focada na materialidade e no âmbito do Estado para pensar o território e as relações espaciais de poder. Nas palavras desses autores:

De modo bem genérico, com algumas raras exceções, a Geografia Política do século $X X$ foi uma geografia do Estado. Em certo sentido, uma geografia política unidimensional que não quis ver no fato político mais que uma expressão do Estado. Na verdade, o fato político penetrou toda a sociedade e, se o Estado é triunfante, não deixa de ser um centro de conflitos e de oposições - em resumo, um lugar de relações de poder que, apesar de dissimétricas, não deixam de ser presentes e reais. Mas a geografia do Estado apagou esses conflitos, que apesar de tudo continuam a existir em todos os níveis relacionais que postulam uma geografia política multidimensional. Essa geografia do Estado foi um fator de ordem ao privilegiar o concebido em detrimento do vivido [citando os conceitos de Henri Lefebvre]". (RAFFESTIN, 1993[1980], p.22)

A reflexão sobre as relações entre o poder e o espaço [...] Era estranha à Geografia Política de princípios do século e à sua variante aplicada, a Geopolítica, cujas interpretações nazistas deixaram tristes lembranças: por não se interessarem pelos processos elementares que estruturam os corpos sociais, essas disciplinas ofereciam explicações muito parciais da formação dos Estados, problema ao qual dedicavam o essencial de seus esforços. (CLAVAL, 1979[1978], p. 9).

Todavia, é fato que Jean Gottmann (1973), autor que pelo menos desde a década de 1950 se dedicou a pesquisar e discorrer sobre o conceito de território, muito parece ter contribuído a essa reflexão, e o fez antes mesmo desse movimento 
mais amplo da Teoria Social Crítica discorrido previamente neste artigo ter tido grande disseminação na Geografia. Muito embora sua obra não tenha o mesmo teor de manifesto nem o mesmo refinamento teórico que as de Raffesttin (1993[1980]) e Claval (1979[1978]), ele é reconhecido por ambos como uma relevante influência rumo à ruptura que eles pregam para com uma Geografia Política reinante até a década de 1970.

Além de ter o mérito de ter sido um dos primeiros a romper com um prisma que somente pensava o território a partir do Estado Nação Moderno, Gottmann também deu significativa contribuição à incorporação da dimensão simbólica por esse conceito. Afirmava ele, em obra do início da década de 1970, que "O significado do território mudou consideravelmente no passado e mesmo durante o século XX"8 (GOTTMANN, 1973, p.3); que em seu caráter empírico, "no seu uso moderno e legal, ele designa uma porção do espaço geográfico sob jurisdição de um certo povo [por meio do Estado-Nação] (GOTTMANN, 1973, p.5)", mas como ferramenta analítica e conceitual voltada ao entendimento de casos diversos (e não apenas aqueles referentes ao Estado Moderno), seria melhor "pensá-lo como a expressão geográfica tanto de uma função social quanto de uma instituição enraizada no psicológico das pessoas" (GOTTMANN, 1973, p.7).

Assim, liberto desse prisma unidimensional, afirma o autor, "o conceito [de território] parece antes designar a relação entre uma comunidade de pessoas organizadas e seu espaço" (GOTTMANN, 1973, p. 123), indicando que "apesar de ser uma entidade substancial, material, mensurável e concreta, [o território] é sem dúvida a expressão de aspectos psicológicos dos grupos humanos" (GOTTMANN, 1973, p.15), os quais pesam tanto na definição de seus limites quanto os aspectos demográficos ou econômicos, sobre os quais mais comumente se buscava sua natureza (GOTTMANN, 1973).

O autor defende, portanto, que aquilo que ele está a chamar de "psicologia" (que seria o simbolismo de uma forma geral) seria tão influente sobre as relações territoriais quanto os meios materiais, tangíveis (GOTTMANN, 1973, p. 54), reconhecendo ele - ainda que sem fazer uso do arcabouço conceitual que foi desenvolvido para se construir essa ponte entre a materialidade e o simbolismo - a importância dessa dimensão imaterial sobre as relações espaciais de poder.

Tanto Raffestin (1993[1980]) quanto Claval (1979[1978]), em suas respectivas obras de fins da década de 1970, aprofundam essa discussão sobre a dimensão

\footnotetext{
8 Todas as traduções desta obra aqui utilizadas são livres.
} 
simbólica das relações espaciais de poder, incorporando em suas análises as premissas teóricas e conceituais sobre as quais se discorreu no item anterior, refinando, por assim dizer, o instrumental teórico-conceitual utilizado na análise das relações espaciais de poder. Raffestin (1993[1980]), especificamente, se consolidou como um importante autor da Geografia cujo trabalho consagrou o conceito de território nas últimas décadas. Ele deixa bem claro como enxerga a relação entre esse conceito e a categoria fundamental da Geografia - o espaço:

\begin{abstract}
É essencial compreender bem que o espaço é anterior ao território. O território se forma a partir do espaço, é o resultado de uma ação conduzida por um ator sintagmático (ator que realiza um programa) em qualquer nível. Ao se apropriar de um espaço, concreta ou abstratamente (por exemplo, pela representação), o ator "territorializa" o espaço.

O espaço é, de certa forma, "dado" como se fosse uma matéria-prima. Preexiste a qualquer ação. "Local" de possibilidades, é a realidade material preexistente a qualquer conhecimento e a qualquer prática dos quais será o objeto a partir do momento em que um ator manifeste a intenção de dele se apropriar. Evidentemente, o território se apoia no espaço, mas não é o espaço. (RAFFESTIN, 1993[1980], p.143).
\end{abstract}

Como se constata na referente citação, esse autor também utiliza o conceito de representações como meio de articular as dimensões materiais e simbólicas das relações territoriais e enfatiza que produzir representações do espaço já é em si uma forma de se apropriar do mesmo, por conta das propriedades intrínsecas das representações - ou seja, influenciar identidades e comportamentos e dar existência, assim, àquilo que enunciam:

\footnotetext{
Produzir uma representação do espaço já é uma forma de apropriação [desse espaço]. [...] qualquer projeto no espaço que é expresso por uma representação revela a imagem desejada de um território, de um local de relações.

Todo projeto [de apropriação do espaço] é sustentado por um conhecimento e uma prática, isto é, por ações e comportamentos que, é claro, supõem a posse de códigos, de sistemas sêmicos. É por esses sistemas sêmicos que se realizam as objetivações do espaço, que são processos sociais. É preciso, pois, que o espaço representado é uma relação e que suas propriedades são reveladas por meio de códigos e de sistemas sêmicos [...] (RAFFESTIN, 1993[1980], p.144).
}

Outro trabalho de grande relevância acerca dessa temática - e que igualmente se converteu em referência quase obrigatória para a discussão acerca das relações espaciais de poder e do conceito de território - é o de Robert David Sack (1986), que se dedicou principalmente a refletir sobre a territorialidade, conceito do qual trataremos a seguir. Convém mencionar aqui, por hora, que ele também ressalta a importância da dimensão simbólica nas relações espaciais de poder, entendendo que um território é o resultado da forma como um determinado 
grupo dá sentido a uma porção do espaço e dele faz uso, por consequência (SACK, 1986).

A esse respeito, o equívoco aparente de Sack (1986) foi pensar que esse tipo de relação simbólico-afetiva-identitária para com o espaço só existe plenamente entre os povos "primitivos", quando de fato ela permeia um amplo leque de atores sociais. Dando-nos o direito efetuar essa pequena retificação às suas ideias, podese afirmar que Sack (1986) já ressaltava o papel que o espaço - assim convertido em território e, portanto, não mais simplesmente um espaço indiferenciado - passa a ter sobre a identidade do grupo e dos indivíduos que o compõem.

Como se constata nesses citados autores, os quais se converteram em referências quase obrigatórias para abordagens sobre as relações espaciais de poder, a trajetória da utilização e ressemantização desse conceito na Geografia ocorreu no sentido de dotá-lo de maior capacidade de apreender a complexidade das inter-relações existentes entre as dimensões material e simbólica das relações espaciais de poder, objetivo para o qual a ponte construída pelo conceito de representações muito contribuiu, como se constata explicitamente em obras clássicas como as de Raffestin (1993[1980]) e em trabalhos contemporâneos, como os de Haesbaert (2010; 2012), Moraes (2005), Claval (2012), dentre outros.

Ao passo que essa mudança de foco ocorria, ampliando a apreensão do universo simbólico, gradativamente ampliava-se a interseção entre o conceito de território e a forma como autores da Geografia mais fundados na fenomenologia concebiam os conceitos de lugar e paisagem, e também em relação à forma como a Antropologia predominantemente fazia uso desse conceito (território), uma vez que ao longo do desenvolvimento desta disciplina seu foco foi a apreensão da dimensão simbólico-afetiva-identitária das relações espaciais ${ }^{9}$. Nas palavras de Haesbaert (2012):

[...] uma noção de território que despreze sua dimensão simbólica, mesmo entre aquelas que enfatizam seu caráter eminentemente político, está fadada a compreender apenas uma parte dos complexos meandros dos laços entre espaço e poder. [...] o poder como relação, e não como coisa a qual possuímos ou da qual somos expropriados, envolve não apenas as relações sociais concretas, mas também as representações que elas veiculam e, de certa forma, também produzem. Assim, não há como separar o poder político mais estrito do poder simbólico.

Criar novos recortes territoriais é ao mesmo tempo um ato de poder no sentido mais concreto e o reconhecimento e/ou a criação de novas referências espaciais de representação social. Pode-se, com um novo

\footnotetext{
${ }^{9}$ Interessante notar que a Antropologia contemporânea buscou atingir semelhante objetivo (superar a dualidade objetividade-subjetividade no uso desse conceito), porém o fez, como se constata em Little (2002), a partir da maior incorporação da dimensão material do território, por muito tempo fora do foco de muitos dos pesquisadores dessa área.
} 
recorte ou "fronteira", legitimar certas identificações sociais previamente existentes ou, o que é mais comum, ao mesmo tempo criar ou fortalecer outras. Como todo processo de representação territorial é altamente seletivo [...], somente alguns espaços serão "representativos" da(s) identidade(s) que eles ajudam a produzir ou reforçar. (HAESBAERT, 2012, p. 92-3, grifo nosso)

Desta forma, a libertação do conceito de território deste prisma unidimensional parece ter feito com que os autores da Geografia cada vez mais percebessem a importância da compreensão da alteridade para análise das relações espaciais de poder (ou seja, de entender "o outro" e forma como ele se relaciona com seu território) e que, sem isso, tem-se a redução do território à mera materialidade do espacial, o que acaba por perpetuar a noção de espaço como mera superfície e/ou distância, da qual fala Massey (2013), que é exatamente a forma como o capital e os colonizadores enxergavam o espaço e que, não por acaso, emerge com o surgimento do capitalismo e sua ascensão a partir da Modernidade, sobretudo por meio da Cartografia Moderna, que historicamente foi construída para viabilizar seu processo de expansão. Nas palavras de Massey (2013):

[...] Conceber o espaço como nas viagens de descobertas, como algo a ser atravessado e, talvez, conquistado, tem implicações específicas. [...] faz o espaço parecer uma superfície, contínuo e tido como algo dado. [...] esse modo de conceber o espaço pode assim, facilmente, nos levar a conceber outros lugares, outros povos, culturas, simplesmente como um fenômeno "sobre" essa superfície. Não é uma manobra inocente; desta forma eles ficam desprovidos de história. [...] Lá estão eles, no espaço, no lugar, sem suas próprias trajetórias. Tal espaço torna mais difícil ver, em nossa imaginação, as histórias que [...] também estavam vivendo e produzindo. (MASSEY, 2013, p.22-23)

Conforme já ressaltava Raffestin (1993[1980], p. 208) a "homogeneidade, a isotropia, e a transparência do espaço" que fundamentam o comportamento desses sujeitos que personificam a lógica do capital são "propriedades que só existem no nível de uma representação e de forma alguma na realidade territorial vivida". Esses supostos obstáculos à lógica do capital, deve-se dizer, foram e ainda são em geral os territórios pré-existentes sobre os quais os agentes que personificam esses interesses pretendem fazer avançar seus empreendimentos, integrando esse recorte ao seu espaço abstrato-funcional, plano, horizontal, estático e moldável.

Como afirma Massey (2013), esse viés usurpador não enxerga um território, ou seja, grupos sociais com temporalidades próprias e que atribuem significados próprios para o espaço e nutrem diferentes maneiras de se relacionar com ele. Ele vê simplesmente uma superfície, plana e moldável, como a escritura, de que fala De Certeau (2005), desprovida de uma temporalidade própria ou mesmo 
completamente atemporal, aguardando apenas serem inseridas no (suposto) tempo único e linear da Modernidade, do capitalismo. Não seria maniqueísmo, portanto, afirmar que essa perspectiva unidimensional-materialista é característica de todos aqueles atores que estão a usurpar (ou almejam usurpar) o território alheio, não obstante após a conquista de novas áreas (a consumação da usurpação territorial, caso se prefira não usar eufemismos), quando esse novo ator permanece sobre esse espaço por algum tempo, ele possa vir a constituir para com ele uma relação de afetividade-identidade.

Todas essas transformações sobre o conceito de território tiveram como corolário a necessidade de se desenvolver/aprimorar conceitos correlatos, como o de territorialidade, de forma a torná-lo uma ferramenta eficaz para se apreender essa complexidade das inter-relações entre o material e o simbólico. Sob este prisma, cada vez mais os autores da Geografia parecem ter despertado para o fato de que as representações de tempo-espaço são um elemento capital da territorialidade de praticamente qualquer grupo social, sendo fundamental tanto à legitimação de seu domínio perante os outros grupos sociais quanto à constituição de laços afetivos-identitários entre os membros do grupo territorializado e essa porção do espaço (agora convertida em território). Utilizando os conceitos de Foucault (2004), pode-se dizer que os discursos dos sujeitos em litígio territorial são impregnados por representações do espaço - ou, melhor, de tempo-espaço, já que essa é outra visão dicotômica ainda a ser superada pela Teoria Social Crítica, como bem apontam autores como Wallerstein (2006) e Massey (2013).

A esse respeito, há que atentar-se aqui para o fato de que por um certo corporativismo ingênuo, temos uma tendência intrínseca, ao menos na Geografia, em invocarmos os mapas, a Cartografia Moderna tal qual a conhecemos, sempre que falamos de representações do espaço. Deixe-se claro: não se questiona aqui a importância da Cartografia para essa ou qualquer outra área do saber, mas seus reflexos sobre a sociedade, sua cultura hegemônica, as representações espaçotemporais que permeiam o seu imaginário. Como ressalta Massey (2013), a Cartografia Moderna foi uma dos principais meios de difusão da noção de espaço como uma dimensão estática, sem movimento, sem vida, em contraposição ao tempo, ao passo que as representações espaciais mais dinâmicas (embutidas de temporalidade) mais frequentemente são difundidas por outras linguagens que não a Cartografia, as quais vão desde o cinema e as artes visuais em geral até a 
linguagem escrita tradicional (por meio da literatura e a historiografia) e mesmo a oralidade.

Em consonância com a histórica hegemonia do tempo sobre o espaço na Filosofia e nas Ciências Sociais, muito tem se refletido sobre o papel do tempo e de suas representações na construção das identidades individuais e coletivas. Esse tem sido o foco desde trabalhos que remontam a meados do século $X X$, como as reflexões sobre memória coletiva de Halbwach (2003), até trabalhos mais contemporâneos, como os de Pollack (1989; 1992). Todavia, é preciso considerar, como ressalta Massey (2013, p. 15), que também "[...] o espaço é uma dimensão implícita que molda nossas cosmologias estruturantes" e que ele, tal qual o tempo, "modula nossos entendimentos do mundo, nossas atitudes frente aos outros, nossa política" e mesmo a forma como "desenvolvemos e praticamos um sentido de lugar" (ou de território, como preferimos aqui abordar).

Tão influentes sobre as identidades e comportamentos individuais e coletivos quanto às demais representações do universo social são, portanto, as representações do espaço - ou melhor, do tempo-espaço, já que essas dimensões da vida social são indissociáveis e estão intrinsecamente relacionadas. Segundo Hall (2016), tal fato está diretamente relacionado a um componente étnico que, ainda que por vezes imperceptível, transpassa nossas diversas identidades:

[...] Não há forma, me parece, pela qual as pessoas do mundo podem agir, falar, criar, vir das margens e dizer, começar a refletir sobre sua experiência se não vierem de algum lugar, elas vêm de alguma história, herdam certas tradições culturais. [...] Você tem que se posicionar em algum lugar para dizer qualquer coisa. Portanto, não podemos evitar que o sentido de nossa própria posição está conotado pelo termo etnicidade. [...] o passado não é apenas uma posição de fala, mas é também uma fonte absolutamente necessária do que se tem a dizer. Não há forma, na minha maneira de ver, na qual esses elementos de etnicidade, que dependem do entendimento do passado, do entendimento de suas raízes, possam ser evitados. (HALL, 2016, -p. 325-326)

$\mathrm{E}$, nesse sentido, o autor também ressalta que a construção dessas identidades ou, como ele prefere dizer, dessas etnicidades - tem como componente fundamental as representações de tempo-espaço:

[...] a ideia de que há identidade fora da representação - de que há um nós mesmos e uma linguagem pela qual nos descrevemos - é insustentável. A identidade está dentro do discurso, dentro da representação. Está construída em parte pela representação. A identidade é uma narrativa do eu; é a história que nós contamos sobre o eu para sabermos quem somos. $[\ldots]$

[...] o tipo de etnicidade que eu estou falando não é simples, essencial - é construída. É construída na história, é construída em parte politicamente. É parte de uma narrativa. Contamos a nós mesmos as histórias de nossas raízes para ter contato, criativamente, com isso. Então essa nova forma de 
etnicidade - as etnicidades emergentes - tem uma relação com o passado, mas é uma relação que é parte pela memória, parte pela narrativa, que tem que ser recuperada. É um ato de recuperação cultural. (HALL, 2016, p.324;326)

Nesse sentido, como Edward Soja já havia destacado (apud Raffestin, 1993 [1980], p.162), não existe territorialidade sem identidade. A esse respeito, deve-se destacar que é imprescindível não tomar a identidade sob um prisma essencialista, individualista, hermética. Tanto sob um prisma individual quanto coletivo, ela deve ser entendida sob um prisma relacional e processual, como uma construção social, conforme ressalta Young (2004) ${ }^{10}$ :

O indivíduo é produto do processo social e não sua origem. [...] A teoria de ação comunicativa concebe a identidade individual não como origem, mas como produto de interações e práticas linguísticas. [...]

grupos [sociais] [...] só existem em relação a outros grupos. Um grupo pode ser identificado por pessoas de fora dele sem que aqueles assim identificados tenham nenhuma consciência de si mesmos como um grupo. Algumas vezes, um grupo vem à existência meramente porque um grupo excluiu e nomeou uma categoria de pessoas, e aqueles assim rotulados lentamente se perceberam como membros de um grupo, com fundamento na opressão compartilhada (YOUNG, 2004, p. 45-46, tradução livre).

Essa discussão está presente na obra de Raffestin (1993[1980]) quando ele destaca que o território é o produto de um ator sintagmático, diferenciando estes dos atores paradigmáticos:

[é preciso] distinguir dois tipos de atores coletivos: aqueles que realizam um programa e que Greimas chama sintagmáticos e aqueles que surgem de uma classificação, de uma repartição [de uma representação social, poderse-ia dizer], sem integração num processo programado e que o mesmo autor chama de paradigmáticos. O ator sintagmático, manifesta, com precisão, a idéia [sic] de processos e articulações sucessivas no interior do processo. Assim, todas as organizações, da família ao Estado, passando pelos partidos, pelas igrejas e pelas empresas, são atores sintagmáticos. $O$ ator sintagmático combina todas as espécies de elementos para "produzir', lato sensu, uma ou várias coisas. O Estado é um ator sintagmático por excelência quando empreende uma reforma agrária, organiza o território, constrói uma rede rodoviária, etc. A empresa é um ator sintagmático quando realiza um programa de produção. Isso significa que 0 ator sintagmático articula momentos diferentes da realização do seu programa pela integração de capacidades múltiplas e variadas. Esses atores sintagmáticos são, portanto, constituídos por atores individuais que se integram ou são integrados num processo programado. (RAFFESTIN, 1993[1980], p. 40).

Esse "ator sintagmático" de que fala Raffestin (1993[1980]) é, antes de tudo, um sujeito coletivo, um coletivo que se reconhece como um grupo social, entendendo que, nas palavras de Young (2004, p.43), eles "não são simplesmente um conjunto de pessoas", mas sim um conjunto de pessoas que "estão

\footnotetext{
10 Todas as traduções desta obra aqui utilizadas são livres.
} 
fundamentalmente interligadas por conta da identidade descrita como pertencentes a elas", "diferenciadas de pelo menos um outro grupo por características culturais, práticas ou estilo de vida"11.

Como afirma Hall (2016, p. 323), "não há identidade que esteja fora da relação dialógica com o Outro". Trata-se de uma construção social de caráter processual, em eterna transformação. Um sujeito existe apenas em relação a pelo menos um outro sujeito. E um grupo social só existe em relação a outro. E sob essa perspectiva relacional, quais traços um grupo utiliza para se distinguir dos demais depende fundamentalmente de quem são esses outros com quem ele se relaciona, como já ressaltam há décadas antropólogos como Barth (2000) e Oliveira (1976).

A existência do território é fruto da relação entre um grupo social e uma certa porção do espaço, assim convertida em seu território, e sua territorialidade, portanto, além de ter sempre algo de idiossincrático, fruto dessa relação histórica entre o grupo e aquela porção do espaço, tende a ter também, em certa medida, um caráter relacional, sobretudo no que tange à sua estratégia para assegurar o domínio sobre aquela porção do espaço convertida (ou que se almeja converter) em seu território. Talvez o aspecto mais amplo e comum desse fenômeno seja aquele do qual se está a tratar aqui, ou seja, a utilização das representações espaço-temporais para fortalecer os vínculos afetivos entre o grupo e aquela porção do espaço e para tentar legitimar, para si e para os "outros", seu domínio daquela porção do espaço.

Neste ponto a Geografia e a Antropologia aparentemente têm convergido em uma trajetória que fora iniciada em pontos de partida opostos, parecendo haver um relativo consenso sobre esse conceito atualmente em ambas disciplinas, fruto deste mesmo movimento de superação da dicotomia materialidade $x$ simbolismo na Teoria Social Crítica. Robert Sack (1986), por exemplo, que é geógrafo, definiu a territorialidade como "uma estratégia espacial para afetar, influenciar ou controlar recursos e pessoas, controlando uma área" (SACK, 1986, p.1) ${ }^{12}$, algo relativamente próximo ao que, por exemplo, propõe Little (2002), pensador oriundo da Antropologia, que a define como o "esforço coletivo de um grupo social para ocupar, controlar, e se identificar com uma parcela específica de seu ambiente biofísico, convertendo-o, assim, em seu território" (LITTLE, 2002, p.3), sendo fundamentais para esse fim, além do conhecimento desse espaço propriamente dito, "as ideologias [...] e identidades" (LITTLE, 2002, p.4).

\footnotetext{
11 Todas as traduções dessa obra aqui utilizadas são livres.

12 Tradução livre.
} 
Definições de territorialidade como essas, portanto, são mais adequadas a uma abordagem não-dicotômica das relações espaciais de poder, pois possuem grande capacidade de captar as formas não tão visíveis, implícitas, pelas quais um grupo social tenta assegurar o domínio sobre uma porção do espaço, sobretudo por reconhecer que o esforço para fortalecer a identificação do grupo para com o território é um dos elementos que caracterizam a territorialidade. Essa tipo de definição conceitual nos permite enxergar que a relação entre a identidade do grupo e as representações do tempo-espaço que constitui seu território têm forte influência sobre sua territorialidade e que estes processos podem ocorrer espontaneamente ou de maneira programática, quando o sujeito do território busca construir e impor representações desse recorte espaço-temporal no intuito específico de fomentar sua vinculação à identidade coletiva do grupo, partindo da premissa de que quanto maior for o peso desse vínculo espacial enquanto traço identitário, mais intensos tendem a ser seus esforços para manter esse território. O exemplo mais clássico dessa ação programática certamente é o Estado-Nação Moderno, como se constata nas obras de Anderson (2008), Hobsbawn (2002; 2015; 2016), Moraes (2005), Tuan (1983; 2012), dentre outros.

Essa importância das representações de tempo-espaço enquanto fundamento da territorialidade pode ser percebido em praticamente qualquer situação de litígio. Elas são um dos meios mais utilizados para se ativar e fortalecer a territorialidade de um grupo, e absolutamente não é coincidência que isso ocorra de forma muito mais latente ante um litígio iminente, quando há uma ameaça ao território, situação em que essas representações se colocam sob os holofotes dos discursos entre os sujeitos envolvidos no litígio.

Por essas razões, a superação do prisma unidimensional de análise das relações espaciais de poder contribuiu significativamente para que os autores da Geografia cada vez mais reconhecessem que as lutas pelo espaço stricto sensu frequentemente são também lutas discursivas, pela imposição das representações desse espaço, e que, portanto, a territorialidade de cada grupo social está intimamente relacionada à produção, disseminação e imposição de representações de tempo-espaço, haja vista sua influência sobre as identidades individuais e coletivas e o fato de que, em situações de litígio, essas representações rapidamente tendem a ser colocadas sob os holofotes do discurso do grupo. 


\section{Considerações Finais}

Os anos de 1970 marcam uma ruptura nos estudos das relações de poder por parte da Geografia, tendo sido desde então cada vez mais pacífico dentre seus autores que o material e o simbólico estão imbricados e se influenciam reciprocamente - são dois campos de batalha de uma mesma guerra.

Em consonância com o que ocorria em outras áreas do saber na segunda metade do século XX, os autores da Geografia parecem ter cada vez mais reconhecendo o papel do universo simbólico nas relações espaciais de poder e partido da premissa de que tais relações não podem ser plenamente compreendidas de forma dissociada dos vínculos de afetividade, identificação e pertencimento para com a porção do espaço feita (ou que se pretende fazer) território.

Este processo teve como corolário uma série de transformações sobre seu arcabouço teórico-conceitual, o que resultou, dentre outras coisas, em novas formas de concepção e uso dos conceitos de território e territorialidade, no sentido de romper com usos predominantemente unidimensionais (essencialmente materialistas) que a Geografia tradicionalmente fez de tais conceitos e, assim, dotálos de maior capacidade de apreender essa complexa inter-relação entre o simbolismo e a materialidade, tornando-os assim ferramentas mais eficazes para se produzir interpretações holísticas, não dicotômicas, das relações espaciais de poder.

$\mathrm{Na}$ Geografia brasileira, especificamente, os reflexos dessas transformações teórico-conceituais podem ser constatados até mesmo em obras daquele que é considerado seu maior nome, nacional e internacionalmente, e cujos trabalhos tinham como principal foco exatamente as questões epistemológicas e metodológicas da disciplina: Milton Santos. Se nas obras que o consagraram, em sua maioria publicadas nas décadas de 1970 e 1980, esse autor fazia um uso unidimensional deste conceito, limitando-o à dimensão material do espaço, em seus trabalhos mais tardios ele parece incorporar essas transformações e fazer um adendo à sua constelação de conceitos, dando um caráter menos dicotômico ao território, como se constata nas conceituações de "território usado" e/ou "território como abrigo", presente em alguns de seus últimos trabalhos, como se constata em Santos $(1994 ; 2011)$. 


\section{Referências}

ANDERSON, Benedict. Comunidades imaginadas: reflexões sobre a origem e difusão do nacionalismo. São Paulo: Companhia das Letras, 2008.

ANDRADE, Manoel Correia de. Geografia: Ciência da Sociedade. Uma Introdução à Análise do Pensamento Geográfico. 1. ed. São Paulo: Atlas, 1987.

BOURDIEU, Pierre. O poder simbólico. 16. ed. Rio de Janeiro, Bertrand Brasil, 2012.

CASTORIADIS, Cornelius. A instituição imaginária da sociedade. 2. ed. Rio de Janeiro: Paz e Terra, 1982.

CHARTIER, Roger. A história cultural: entre práticas e representações. Rio de Janeiro: Bertrand Brasil, 1990.

CLAVAL, Paul. Espaço e Poder. Rio de Janeiro: Zahar Editores, 1979 [1978].

CLAVAL, Paul. Epistemologia da Geografia. Florianópolis: Editora UFSC, 2012.

DE CERTEAU, Michel. A invenção do cotidiano: 1. Artes de fazer. 11. Ed. Petrópolis, Editora Vozes: 2005.

FOUCAULT, Michel. Microfísica do poder. 20. ed. Rio de Janeiro: Edições Graal, 2004.

GODELIER, Maurice. A parte ideal do real. In: Carvalho, Edgar de Assis (Org.).

Antropologia. São Paulo: Ática, 1981.

GOTTMANN, Jean. The significance of territory. Charlottesville: The University Press of Virginia, 1973.

HAESBAERT, Rogério. O mito da desterritorialização. 7. ed. Rio de Janeiro: Bertrand Brasil, 2012.

HAESBAERT, Rogério. Regional-Global. Dilemas da Região e da Regionalização na Geografia Contemporânea. Rio de Janeiro: Bertrand Brasil, 2010.

HALBWACH, Maurice. A memória coletiva. São Paulo: Centauro, 2003.

HALL, Stuart. Etnicidade: identidade e diferença. Crítica cultural - Critic, Palhoça, SC, v.11, n.2, p.317-327, jul./dez.2016.

HOBSBAWN, Eric. A invenção das tradições. São Paulo: Paz e Terra, 2016.

HOBSBAWN, Eric. Era do Capital (1848-1875). 27. ed. São Paulo: Editora Paz e Terra, 2015.

HOBSBAWN, Eric. Nações e nacionalismos: desde 1870. São Paulo: Paz e Terra, 2002.

MASSEY, Doreen. Pelo Espaço. 4. ed. Uma nova política da espacialidade. 4a ed. Rio de Janeiro: Bertrand Brasil, 2013.

MORAES, Antônio Carlos Robert. Geografia: pequena história crítica. São Paulo: Annablume, 2007.

MORAES, Antônio Carlos Robert. Território e História no Brasil. 2. ed. São Paulo: Annablume, 2005. 
POLLACK, Michael. Memória, Esquecimento, Silêncio. Revista Estudos Históricos, Rio de Janeiro, vol. 2, n. 3, 1989. p. 3-15.

POLLACK, Michael. Memória e Identidade Social. Revista Estudos Históricos, Rio de Janeiro, vol. 5, n. 10, 1992, p. 200-212.

RAFFESTIN, Claude. Por uma Geografia do Poder. São Paulo: Editora Ática, 1993 [1980].

SACK, Robert David. Human Territoriality: its theory and history. Cambridge: Cambridge University Press, 1986.

SANTOS, Milton. O retorno do Território. In: SANTOS, M; SOUZA, M.A. de; SILVEIRA, M.L. Território - Globalização e Fragmentação. São Paulo: Hucitec, 1994.

SANTOS, Milton. Por uma outra globalização. 20. ed. Do pensamento único à consciência universal. São Paulo: Editora Record, 2011.

TUAN, Yi Fu. Espaço e Lugar. São Paulo: Difel, 1983.

TUAN, Yi Fu. Topofilia. Um estudo da percepção, atitudes e valores do meio ambiente. Londrina: Eduel, 2012.

WALLERSTEIN, Immanuel. Impensar a Ciência Social. Os limites dos paradigmas do século XIX. Aparecida, SP: Idéias \& Letras, 2006.

YOUNG, Iris. Five Faces of Oppression. In: HELDKE, Lisa, e O'CONNOR, Peg. Opression, Privilege and Resistance. Boston: Mcgraw Hill, 2004.

\section{NOTAS DE AUTOR}

CONTRIBUIÇÃO DE AUTORIA

Jaime Bernardo Neto - Concepção. Elaboração do manuscrito, revisão e aprovação da versão final do trabalho.

\section{FINANCIAMENTO}

Não se aplica.

CONSENTIMENTO DE USO DE IMAGEM

Não se aplica.

APROVAÇÃO DE COMITÊ DE ÉTICA EM PESQUISA

Não se aplica.

CONFLITO DE INTERESSES

Não se aplica.

\section{LICENÇA DE USO}

Este artigo está licenciado sob a Licença Creative Commons CC-BY. Com essa licença você pode compartilhar, adaptar, criar para qualquer fim, desde que atribua a autoria da obra.

\section{HISTÓRICO}

Recebido em: 12-04-2020

Aprovado em: 03-10-2020 